\title{
Investing on Occupational Safety and Health
}

\author{
Pranab Dahal
}

Linnaeus University, Kalmar, Sweden

S afety and health issues are central to every sphere of life but this issue becomes more paramount when workplace is concerned. A worker contributes an average of one third of the day or even more, utilizing their physical and mental capabilities to producing both tangible and intangible products. In the given backdrop, if the workplace remains a shaded grey zone undermining the health and safety, fatalities and productive losses catches up soon thereby reducing the chances of growth and sustenance of any given enterprise.

The occupational safety and health programs equip sectors to overcome workplace hostility producing elated employees and safer workplace. Research proves that the employees are motivated to work in conditions where safety and health issues are prioritized, a study finds that sixty-one percent of the workers confirmed of doing more hard work for the employee investing on their safety and health issues. ${ }^{1}$ The investment on occupational safety and health like any other investments yields benefits to the investors. A study conducted on the costs and benefits of investments in occupational safety and health in the companies identifies that the return on prevention ratio is 2.2 , this infers that an investment of one currency unit per year per employee the companies are expected to earn 2.2 currency unit. $^{2}$ Together with an increase in profitability, the apparatus of occupational safety and health also helps to reduce social cost associated with loss of productivity, function and welfare costs. ${ }^{3}$

The occupational safety and health management systems have been a recent development which encompasses a holistic approach and periodic

DOI: https://doi.org/10.3126/ijosh.v7i1.22758

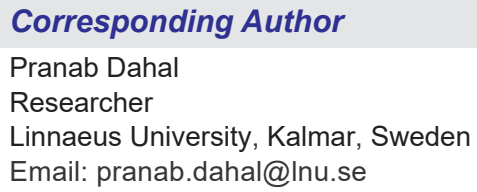

(C) 2017 IJOSH All rights reserved evaluations for increased improvements on occupational safety and health performance. This $\mathrm{OSH}$ management system complies with the legislation and policies and also identifies importance of standardization from any third party giving more credibility for undertaken improvement approaches. Like any systems this system is an iterative process and takes care of technical, behavioral and human aspects related to work and working conditions for increased safety and health concerns. ${ }^{4}$

The investment on the occupational safety and health has to follow a participatory approach where both employees and the employers involved in problem identification and developing hands on solutions for the intervention process and contribute to evaluations of the efforts made for changes. This increases obligation and responsibility bearing at the both ends with active engagements. The investment on occupational safety and health is an investment for future, growth and continued partnership with the workers.

\section{References}

1. Aviva. The fifth Aviva Health of the Workplace Report. [Internet]. London: Aviva Plc. 2011. Available from: www.aviva.co.uk/healthcarezone/document-library/ files/ge/gen4279.pdf

2. Bräunig $\mathrm{D}$, Kohstall $\mathrm{T}$. The return on prevention: Calculating the costs and benefits of investments in occupational safety and health in companies [Internet]. Geneva: International Social Security Association; 2011. Available from: https://www. internationalsosfoundation.org/-/media/internationalsos-foundation/files/resources/international/ medical-and-occupational-helath/the-return-onprevention--costs-and-benefits-of-investments-inoccupational-health.pdf?la=en.

3. EU-OSHA. Inventory of socioeconomic costs of work accidents. 2002. Luxembourg

4. Walters D, James P. What motivates employers to establish preventive management arrangements within supply chains? Safety Science. 2011;49(7):988994. 